Erratum

\title{
Erratum: Nagasawa, K. et al. Phenotypic Stability of Sex and Expression of Sex Identification Markers in the Adult Yesso Scallop Mizuhopecten yessoensis throughout the Reproductive Cycle. Animals 2019, 9(5), 277
}

\author{
Kazue Nagasawa $* \mathbb{B}$, Tongchai Thitiphuree and Makoto Osada * \\ Laboratory of Aquacultural Biology, Graduate School of Agricultural Science, Tohoku University, 468-1 Aoba, \\ Aramaki, Aoba-ku, Sendai, Miyagi 980-8572, Japan \\ * Correspondence: kna@tohoku.ac.jp (K.N.); makoto.osada.a8@tohoku.ac.jp (M.O.); \\ Tel.: +47-22-757-4133 (K.N. \& M.O.); Fax: +81-22-757-4132 (K.N. \& M.O.)
}

Received: 27 August 2019; Accepted: 27 August 2019; Published: 29 August 2019

In the published article, "Phenotypic Stability of Sex and Expression of Sex Identification Markers in the Adult Yesso Scallop Mizuhopecten yessoensis throughout the Reproductive Cycle. Animals 2019, 9(5), 277. doi:10.3390/ani9050277" [1], the proportion numbers in Table 1 are inverted.

In Table 1, the proportion numbers "22:0" and "0:21" should be replaced with "0:22" and "21:0" (Table 1).

Table 1. Changes of sex ratio from one to two years of age in the Yesso scallop.

\begin{tabular}{lccccccc}
\hline Sampling Period (Age) & Mar 2016 (10 Months) & \multicolumn{2}{c}{ Oct 2016 (16 Months) } & \multicolumn{2}{c}{ Dec 2016 (19 Months) } \\
\hline Group & Intact & Survivors & Analyzed & Female:Male Survivors & Analyzed & Female:Male \\
\hline Group A (pro-males) & 140 & 45 & 10 & $0: 10$ & 22 & 22 & $0: 22$ \\
Group B (pro-females) & 150 & 51 & 10 & $10: 0$ & 21 & 21 & $21: 0$ \\
\hline
\end{tabular}

The authors would like to apologize for any inconvenience caused to the readers by this change. The manuscript will be updated and the original copy will remain online on the article webpage.

Conflicts of Interest: The authors declare no conflict of interest.

\section{References}

1. Nagasawa, K.; Thitiphuree, T.; Osada, M. Phenotypic Stability of Sex and Expression of Sex Identification Markers in the Adult Yesso Scallop Mizuhopecten yessoensis throughout the Reproductive Cycle. Animals 2019, 9, 277. [CrossRef]

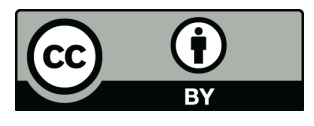

(C) 2019 by the authors. Licensee MDPI, Basel, Switzerland. This article is an open access article distributed under the terms and conditions of the Creative Commons Attribution (CC BY) license (http://creativecommons.org/licenses/by/4.0/). 